\title{
Post-Procedural Anticoagulation After Primary Percutaneous Coronary Intervention for Anterior Acute Myocardial Infarction With Severe Left Ventricular Dysfunction
}

\author{
Peng-fei Chen, MD; Jun-lin Yi, MD; Jun-yu Pei, MD; Liang Tang, MD; \\ Zhen-fei Fang, MD, PhD; Sheng-hua Zhou, MD, PhD; Xin-qun Hu, MD, PhD
}

\begin{abstract}
Background: Patients with anterior acute myocardial infarction (AMI) and left ventricular (LV) dysfunction have an increased risk of LV thrombus (LVT). In the thrombolytic era, short-term anticoagulation using low-molecular-weight heparin during hospitalization proved to significantly reduce LVT formation, but, the effect of this prophylactic approach remains unclear in the current era. Therefore, we conducted a study to evaluate the effects of post-procedural anticoagulation (PPAC) using enoxaparin in addition to dual antiplatelet therapy (DAPT) after primary percutaneous coronary intervention (PCI) in such patients.
\end{abstract}

\begin{abstract}
Methods and Results: A total of 426 anterior AMI patients with LV ejection fraction $\leq 40 \%$ were retrospectively enrolled and classified into 2 groups based on whether they received PPAC (enoxaparin SC for at least 7 days). All patients received primary PCl and DAPT. The primary endpoint was definite LVT at 30 days diagnosed by echocardiography. The secondary endpoints were 30-day mortality, embolic events, and major bleeding events. PPAC was independently associated with a lower incidence of LVT (odds ratio $0.139,95 \%$ confidence interval $0.032-0.606, P=0.009$ ). The 30-day mortality, embolic events, and major bleeding events were not statistically different between groups.
\end{abstract}

Conclusions: Short-term PPAC using enoxaparin after primary PCI may be an effective and safe way to prevent LVT in patients with anterior AMI and LV dysfunction.

Key Words: Acute myocardial infarction; Anticoagulation; Left ventricular thrombus; Percutaneous coronary intervention

$\mathbf{P}$ atients with anterior acute myocardial infarction (AMI) and left ventricular (LV) dysfunction have an increased risk of LV thrombus (LVT) formation, which can lead to systemic embolism and even death. ${ }^{1}$ Although the prevalence of LVT has been reduced with the advent of primary percutaneous coronary intervention (PCI) and routine use of dual antiplatelet therapy (DAPT), a recent meta-analysis showed that $9.1 \%$ of anterior AMI patients were developing LVT in the current era. ${ }^{2}$ Warfarin, as a prophylactic strategy in addition to DAPT after primary PCI, is therefore utilized and was once recommended by guidelines for patients with increased risk of LVT formation. ${ }^{3,4}$ However, results from recent studies and meta-analysis do not support the additional use of warfarin in such patients because it brings no mortality benefit while increasing the frequency of major bleeding..$^{5-7}$ Thus, identifying other safe and effective strategies to prevent LVT formation in high-risk patients remains worthwhile. In the pre-PCI era, short-term anticoagulation using low-molecular-weight heparin (LMWH) during hospitalization was proved to significantly reduce LVT formation in anterior AMI. ${ }^{8-10}$ Furthermore, LMWH seems to have less hemorrhagic risk than that observed with warfarin, and thus may represent a more promising tool for prophylaxis against LVT formation. However, it is unclear whether this prophylactic benefit still exists when patients are managed with primary PCI according to contemporary practice. Despite routine administration of LMWH after primary PCI, known as post-procedure anticoagulation (PPAC), is not recommended in the latest ST-segment elevation myocardial infarction (STEMI) guideline, ${ }^{11}$ so the role of PPAC as prophylaxis against LVT formation in high-risk patients has not been well established. Therefore, the aim of the current study was to evaluate whether inhospital PPAC using enoxaparin after primary PCI contributed to a lower incidence of LVT in patients with anterior AMI and LV dysfunction, and to assess its association with 30-day outcomes.

Received January 14, 2020; revised manuscript received June 15, 2020; accepted June 23, 2020; J-STAGE Advance Publication released online August 26, 2020 Time for primary review: 28 days

Department of Cardiology, The Second Xiangya Hospital of Central South University, Changsha, China

Mailing address: Xin-qun Hu, MD, PhD, Department of Cardiology, The Second Xiangya Hospital of Central South University, No. 139, Middle Ren-min Road, Changsha, Hunan 410011, China. E-mail: hxqsci@csu.edu.cn

All rights are reserved to the Japanese Circulation Society. For permissions, please e-mail: cj@j-circ.or.jp

ISSN-1346-9843 

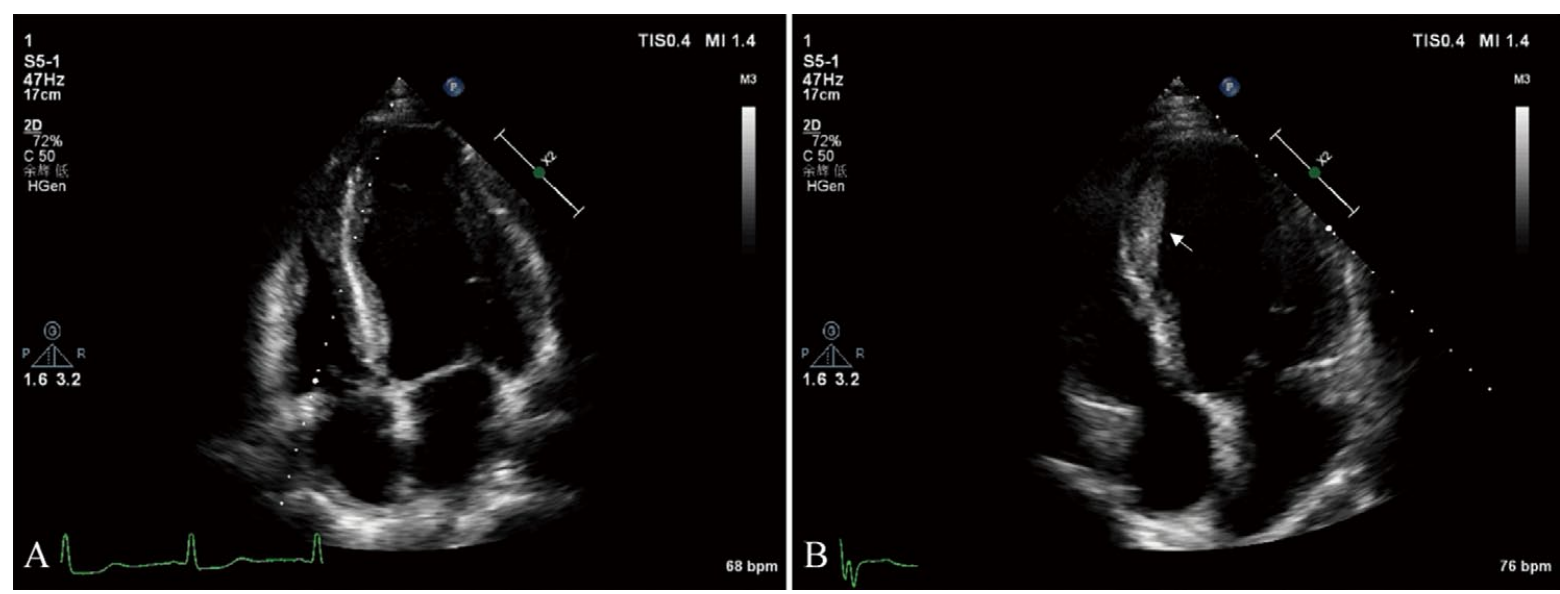

Figure 1. Transthoracic echocardiography revealed the absence of left ventricular thrombus on admission (A), and its presence at 30 days follow-up (B, white arrow).

\section{Methods}

\section{Study Population}

Patients who presented with anterior AMI and LV ejection fraction (LVEF) $\leq 40 \%$ at admission and who underwent primary PCI at the Second Xiangya Hospital between January 2011 and December 2016 were retrospectively enrolled in this study. The diagnosis of anterior AMI was based on chest pain lasting $>30 \mathrm{~min}$, persistent ST-segment elevation $(\geq 0.2 \mathrm{mV})$, or $\mathrm{Q}$ waves in the precordial leads (V1-V6) on 12-lead ECG and later confirmed by increased cardiac markers (e.g., cardiac troponin I (cTnI) $>99$ th percentile upper reference limit). LVEF was obtained from the first transthoracic echocardiography performed within $48 \mathrm{~h}$ of admission. Patients were excluded from the analysis if they (1) presented with LVT or other indications for anticoagulation, including atrial fibrillation, mechanical valves, deep venous thrombosis, etc; (2) had contraindications to anticoagulation; (3) underwent a rescue or planned PCI immediately after thrombolysis; and (4) had records with missing or incomplete data. Patients were classified into 2 groups based on whether they routinely received PPAC therapy. The decision concerning routine PPAC therapy or not was at the physician's discretion. Our departmental policy for routine PPAC was to use enoxaparin $(1 \mathrm{mg} / \mathrm{kg}$, maximum $100 \mathrm{mg}$, SC every $12 \mathrm{~h})$ after primary PCI for 7 days. Enoxaparin was injected in the abdominal region. Baseline demographic, procedural, and echocardiographic data were obtained from the medical records by trained staff. All patients completed 30 days of post-hospitalization follow-up. The study was conducted in accordance with the Declaration of Helsinki.

\section{Standard Therapy}

All patients received $300 \mathrm{mg}$ of aspirin and a loading dose of a P2Y12 receptor inhibitor $(300 \mathrm{mg}$ of clopidogrel or $180 \mathrm{mg}$ of ticagrelor) before primary PCI. An intravenous bolus of weight-adjusted unfractionated heparin was administered to achieve an activated clotting time of 200 $250 \mathrm{~s}$ during the procedure. Additional heparin was given at a dose guided by the activated clotting time. The use of glycoprotein IIb/IIIa inhibitor (tirofiban, intracoronary or intravenous bolus at $25 \mathrm{ug} / \mathrm{kg}$ and $0.15 \mathrm{ug} / \mathrm{kg} / \mathrm{min}$ maintenance infusion for $12-24 \mathrm{~h}$ ) was left to the operator's discretion. Thrombus aspiration was recommended if there was a relevant thrombus. Direct stenting (without balloon predilatation) implantation was performed whenever possible. Post-PCI medication consisted of DAPT with lifelong aspirin $100 \mathrm{mg} /$ day, and clopidogrel $75 \mathrm{mg} /$ day for at least 12 months. Beta-blockers, angiotensin-converting enzyme inhibitors (ACEI), and statins were also given according to current guidelines.

\section{Echocardiographic Assessment of LVT}

The presence of LVT was assessed using transthoracic echocardiography, which was undertaken within $48 \mathrm{~h}$ of admission (baseline data) and repeated at 30-day followup. LVT was defined as an echo-dense mass adjacent to an abnormally contracting myocardial segment. To qualify as LVT, the mass had to be distinguishable from the underlying myocardium, have a clear thrombus blood interface, and be visible in $>2$ views. Echocardiographic findings were interpreted independently by 2 expert cardiologists. Examples of the absence or presence of LVT are illustrated in Figure 1.

\section{Study Endpoint}

The primary endpoint was definite LVT at 30 days diagnosed by echocardiography. Detection of thrombus at baseline was an exclusion criterion for protocol participation. The secondary endpoints were 30-day mortality, embolic events, and major bleeding events. The embolic events were defined as ischemic stroke diagnosed by neurological examination (NIHSS) and MRI scanning, and peripheral embolism verified by angiography. Major bleeding was defined as intracranial hemorrhage, $\geq 5 \mathrm{~g} / \mathrm{dL}$ decrease in hemoglobin concentration or $\geq 15 \%$ absolute decrease in hematocrit according to Thrombolysis in Myocardial Infarction (TIMI) criteria. ${ }^{\mathbf{1 2}}$ The decision on endpoint events was adjudicated through the use of original source documentation by an independent committee unaware of the treatment allocation. 


\begin{tabular}{|c|c|c|c|}
\hline & $\begin{array}{c}\text { PPAC } \\
(n=168)\end{array}$ & $\begin{array}{c}\text { No PPAC } \\
(n=258)\end{array}$ & $P$ value \\
\hline Age (years) & $61(51-71)$ & $62(52-72)$ & 0.212 \\
\hline Male & $134(79.8)$ & $213(82.5)$ & 0.468 \\
\hline Diabetes mellitus & $48(28.6)$ & $42(16.3)$ & 0.002 \\
\hline Hypertension & $105(62.5)$ & $144(55.8)$ & 0.171 \\
\hline Hyperlipidemia & $88(33.3)$ & $86(52.4)$ & $<0.001$ \\
\hline Current smoker & $100(59.5)$ & $152(58.9)$ & 0.901 \\
\hline Prior heart failure & $18(10.7)$ & $24(9.3)$ & 0.633 \\
\hline Prior MI & $17(10.1)$ & $27(10.5)$ & 0.909 \\
\hline Prior stroke & $4(2.4)$ & $18(7)$ & 0.036 \\
\hline Prior $\mathrm{PCl}$ & $24(14.3)$ & $33(12.8)$ & 0.745 \\
\hline Prior CABG & $6(3.6)$ & $6(2.3)$ & 0.448 \\
\hline Heart rate (beats/min) & $84(74-96)$ & $82(73-97)$ & 0.63 \\
\hline $\mathrm{SBP}(\mathrm{mmHg})$ & $119(104-132)$ & $117(101-134)$ & 0.562 \\
\hline $\mathrm{DBP}(\mathrm{mmHg})$ & $74(65-82)$ & $73(65-82)$ & 0.725 \\
\hline Killip class & & & 0.061 \\
\hline I & $13(7.7)$ & $24(9.3)$ & \\
\hline II & $28(16.7)$ & $48(18.6)$ & \\
\hline III & $98(58.3)$ & $118(45.7)$ & \\
\hline IV & $29(17.3)$ & $68(26.4)$ & \\
\hline LVEF at admission (\%) & $25(20-32)$ & $25(19-28)$ & 0.278 \\
\hline LVEF at 30 days (\%) & $22(20-36)$ & $21(14-31)$ & 0.541 \\
\hline Peak troponin I (ng/mL) & $71(39-105)$ & $63(41-112)$ & 0.31 \\
\hline Peak CK (U/L) & $3,243(1,588-3,930)$ & $2,932(1,026-3,012)$ & 0.247 \\
\hline Peak CKMB (U/L) & $311(89-459)$ & $298(67-412)$ & 0.643 \\
\hline NT-proBNP (pg/mL) & $1,861(797-4,767)$ & $1,846(542-3,719)$ & 0.202 \\
\hline eGFR $\left(\mathrm{mL} / \mathrm{min} / 1.73 \mathrm{~m}^{2}\right)$ & $90.5(77-113.5)$ & $99(80.8-112.2)$ & 0.181 \\
\hline Paroxysmal AF & $7(4.2)$ & $12(4.6)$ & 0.813 \\
\hline
\end{tabular}

Data are expressed as mean $\pm S D$, as $n(\%)$, or as median (interquartile range). $A F$, atrial fibrillation; $C A B G$, coronary artery bypass grafting; CK, creatine kinase; CKMB, creatine kinase myocardial bound; DBP, diastolic blood pressure; eGFR, estimated glomerular filtration rate; LVEF, left ventricular ejection fraction; MI, myocardial infarction; NT-proBNP, amino-terminal pro-B-type natriuretic peptide; PCI, percutaneous coronary intervention; PPAC, postprocedural anticoagulation; SBP, systolic blood pressure.

\section{Statistical Analysis}

Continuous variables were tested for normal distribution by the Kolmogorov-Smirnov test. Continuous data are reported as mean $\pm \mathrm{SD}$ or median with 25 th and 75 th percentiles (interquartile range, IQR), if not normally distributed, and were compared using Student's t-test. Categorical data are expressed as percentages and compared by the chi-square test or Fisher's exact test. To account for differences in baseline characteristics, multivariate logistic regression analysis was performed. All variables with $\mathrm{P}$ values $<0.10$ compared between the 2 groups were considered as baseline imbalances and included in the multiple regression model. The enter method and forward-stepwise method were used. All statistical tests were performed using SPSS software, version 17.0 (SPSS Inc., Chicago, IL, USA). $\mathrm{P}<0.05$ was regarded as statistically significant.

\section{Results}

A total of 426 patients were enrolled and of them, 168 $(39.4 \%)$ routinely received PPAC, while $258(60.6 \%)$ did not. The anticoagulant agent used for PPAC in this study was enoxaparin. Baseline clinical characteristics and laboratory variables according to PPAC use are listed in Table 1, and procedural data and concomitant medica- tions are summarized in Table 2. Overall, the PPAC group tended to have more diabetes and multivessel disease but less hyperlipidemia and prior stroke. The patients in the PPAC group were also more likely to be receiving statins and ACEI/angiotensin-receptor blockers (ARB). No significant difference was observed between groups with regard to other baseline clinical characteristics. The baseline laboratory findings and key procedural characteristics were also similar between PPAC groups. Paroxysmal atrial fibrillation occurred in 19 patients: 7 of $168(4.2 \%)$ in the PPAC group and 12 of $258(4.6 \%)$ in the no-PPAC group.

\section{Unadjusted 30-Day Outcomes}

During hospitalization and the 30 days after discharge, patients receiving PPAC had a significantly lower incidence of LVT ( $2.4 \%$ vs. $8.1 \%, \mathrm{P}=0.013)$. There was a trend towards a lower incidence of unadjusted mortality and embolic events in the PPAC group compared with the noPPAC group, but it was statistically non-significant $(2.4 \%$ vs. $4.8 \%, \mathrm{P}=0.228 ; 1.8 \%$ vs. $3.5 \%, \mathrm{P}=0.379$ ). In detail, embolic events occurred in 11 patients: 3 of 168 in the PPAC group ( 2 ischemic strokes, 1 peripheral embolism), and 9 of 258 in the no-PPAC group ( 7 ischemic strokes, 2 peripheral embolism). Major bleeding events occurred in 11 patients: 5 (3\%) of 168 in the PPAC group (1 intracra- 


\begin{tabular}{|c|c|c|c|}
\hline & $\begin{array}{c}\text { PPAC } \\
(n=168)\end{array}$ & $\begin{array}{c}\text { No PPAC } \\
(n=258)\end{array}$ & $P$ value \\
\hline \multicolumn{4}{|l|}{ In-hospital medication } \\
\hline Aspirin & $162(96.4)$ & 247 (95.7) & 0.721 \\
\hline P2Y12 receptor inhibitor & $158(94)$ & $230(89.1)$ & 0.083 \\
\hline Gllb/Illa receptor inhibitor & $182(70.5)$ & $114(67.9)$ & 0.556 \\
\hline$\beta$-blockers & $144(85.7)$ & $205(79.5)$ & 0.101 \\
\hline Statins & $164(97.6)$ & $236(91.5)$ & 0.01 \\
\hline ACEI/ARB & $144(85.7)$ & $166(64.3)$ & $<0.001$ \\
\hline Symptom onset to balloon & $221(142-310)$ & $233(137-319)$ & 0.426 \\
\hline Door-to-balloon & $99(72-144)$ & $101(75-132)$ & 0.232 \\
\hline Multivessel disease & $80(47.6)$ & $94(36.4)$ & 0.022 \\
\hline \multicolumn{4}{|l|}{ Arterial access site } \\
\hline Radial & $148(88.1)$ & $212(82.2)$ & 0.099 \\
\hline Femoral & $38(22.6)$ & $71(27.5)$ & 0.257 \\
\hline Stent implanted & $106(63.1)$ & $151(58.5)$ & 0.346 \\
\hline Thrombus aspiration & $50(29.8)$ & $67(26)$ & 0.391 \\
\hline Pre-PCI TIMI flow & & & 0.185 \\
\hline $0-1$ & $120(71.4)$ & $199(77.1)$ & \\
\hline $2-3$ & $48(28.6)$ & $59(22.9)$ & \\
\hline Post-PCI TIMI flow & & & 0.737 \\
\hline $0-1$ & $20(11.9)$ & $28(10.9)$ & \\
\hline $2-3$ & $148(88.1)$ & $230(89.1)$ & \\
\hline
\end{tabular}

Data are presented as $n$ (\%) or median (interquartile range). ACEl, angiotensin-converting enzyme inhibitors; ARB, angiotensin-receptor blockers; PCI, percutaneous coronary intervention; PPAC, post-procedural anticoagulation; TIMI, Thrombolysis in Myocardial Infarction.

nial hemorrhage, 2 gastrointestinal bleeding, 1 retroperitoneal bleeding and 1 arterial puncture site bleeding), and 6 $(2.3 \%)$ of 258 in the no-PPAC group ( 2 intracranial hemorrhage, 3 gastrointestinal bleeding, 1 urogenital bleeding). The rate of major bleeding events was similar between groups $(\mathrm{P}=0.759)$. The detailed results of the unadjusted 30-day outcomes are presented in Table 3.

\section{Adjusted 30-Day Outcomes}

As shown in Figure 2, the significant decrease in LVT formation observed with PPAC persisted even after adjustment for baseline imbalances, which included history of diabetes mellitus, history of hyperlipidemia, prior stroke, Killip class, P2Y12 receptor inhibitor use, statins use, ACEI/ARB use, multivessel disease and radial artery access site (odds ratio (OR) $0.139,95 \%$ confidence interval (CI) $0.032-0.606, \mathrm{P}=0.009$ ). No independent associations were observed between PPAC and mortality, embolic events, and major bleeding events. We also performed forward-stepwise logistic regression to simplify the regression model. Results also demonstrated the robustness of the association between PPAC and LVT formation (OR $0.150,95 \%$ CI $0.040-0.565, \mathrm{P}=0.005$ ).

\section{Discussion}

The major finding in the present study was that PPAC using enoxaparin after primary PCI was independently associated with a decreased incidence of LVT in patients with anterior AMI and LV dysfunction.

The effect of short-term use of LMWHs for the treatment and prevention of LVT after AMI was well demonstrated in the pre-PCI era. ${ }^{8-10}$ Meurin et al conducted a

\begin{tabular}{|llll|}
\hline \multicolumn{3}{|c|}{ Table 3. Unadjusted Study Outcomes at 30 Days } & \\
& $\begin{array}{c}\text { PPAC } \\
\text { (n=168) }\end{array}$ & $\begin{array}{c}\text { No PPAC } \\
\text { (n=258) }\end{array}$ & P value \\
Primary outcome & & & \\
LVT formation & $4(2.4)$ & $21(8.1)$ & 0.013 \\
Secondary outcomes & & & \\
Mortality & $4(2.4)$ & $12(4.8)$ & 0.228 \\
Embolic events & $3(1.8)$ & $9(3.5)$ & 0.379 \\
Ischemic stroke & $2(1.2)$ & $7(2.7)$ & \\
Peripheral embolism & $1(0.6)$ & $2(0.8)$ & \\
Major bleeding events & $5(3)$ & $6(2.3)$ & 0.759 \\
Intracranial & $1(0.6)$ & $2(0.8)$ & \\
Gastrointestinal & $2(1.2)$ & $3(1.2)$ & \\
Retroperitoneal & $1(0.6)$ & $0(0)$ & \\
Urogenital & $0(0)$ & $1(0.4)$ & \\
Arterial puncture site & $1(0.6)$ & $0(0)$ & \\
\hline
\end{tabular}

Data are presented as $n(\%)$. LVT, left ventricular thrombus; PPAC, post-procedural anticoagulation.

study of enoxaparin for short-term treatment of LVT and showed it is well tolerated and efficient in reducing the size and prevalence of thrombi. ${ }^{13}$ Another study by Kontny et $\mathrm{al}^{\mathbf{8}}$ explored the prophylactic role of LMWH in patients with an AMI treated with thrombolysis. They showed that the addition of dalteparin during hospitalization led to a marked reduction in the formation of LVT compared with placebo ( 13.8 vs. $21.9 \%, \mathrm{P}=0.02$ ). Nevertheless, limited data are available regarding the effect of this prophylactic approach in AMI patients receiving primary PCI and DAPT. One observational study showed that 5 days of 


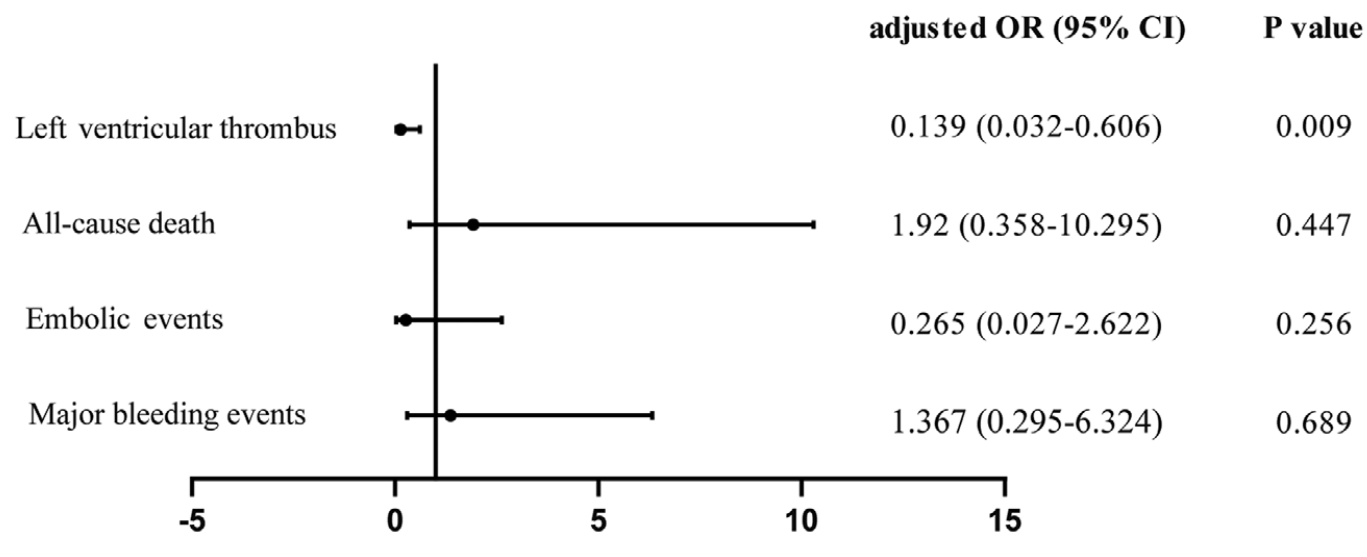

Figure 2. Adjusted study outcomes at 30 days. $\mathrm{Cl}$, confidence interval; OR, odds ratio.

PPAC plus DAPT after primary PCI in patients with anterior AMI was associated with low LVT occurrence $(4.7 \%) .{ }^{14}$ But that study did not have a control group, and thus it was not possible to draw a conclusion on whether short-term PPAC was effective in the prevention of LVT. Another randomized trial chose warfarin as the control group and reported that enoxaparin for 30 days was associated with a numerically higher (not statistically significant) risk of LV thrombus compared with a 3-month course of warfarin. ${ }^{15}$ However, the role of warfarin in preventing LVT remains controversial, which made it difficult to determine the precise contribution of PPAC to the prevention of LVT formation. In the present study, we compared patients who received PPAC (enoxaparin for 7 days after primary $\mathrm{PCI}$ ) with those not receiving PPAC and found that the PPAC group had a significantly lower incidence of LVT. Even after adjusting for differences in baseline variables and other medical treatment, a role of PPAC in preventing LVT still existed. Notably, the prevalence of LVT formation in our study was relatively low compared with that reported in the previous study. ${ }^{2,14,15}$ The underlying reason is unclear, but we suspect it may be that most patients in our study received timely primary PCI, DAPT and optimal heart failure treatment. More importantly, the incidence of major bleeding was not increased in the PPAC group. All included patients received DAPT therapy for a minimum of 1 month, and most of them $(98 \%)$ were recommended to continue this for 12 months. In the PPAC group, patients received enoxaparin. Although the addition of anticoagulant to DAPT, known as triple antithrombotic therapy, has been associated with increases in bleeding events, ${ }^{\mathbf{1 6}-\mathbf{1 8}}$ most studies on this topic have had long-term ( $>6$ months) use of warfarin. One study investigating the short-term (1 month) use of triple antithrombotic therapy found no increase in bleeding complications, ${ }^{\mathbf{1 8}}$ which is consistent with our results. From this perspective, short-term PPAC using enoxaparin might be a preferable prophylactic strategy to prevent LVT formation without increasing the risk of bleeding. However, these results need to be interpreted with caution. There are several types of LMWH with different chemical properties, which may lead to different outcomes. It is unknown whether the effect of preventing LVT exists with other LMWHs. Meanwhile, the optimal duration of PPAC in patients such as those we studied is still unclear.

Our previous analysis had already shown that the presence of LVT after AMI indicates a 4-fold increased embolic risk and 2-fold higher long-term mortality rate. ${ }^{19}$ A reduction in LVT formation is supposed to benefit patients by decreasing mortality and embolic events. However, such benefits were not shown in the present study. Even though mortality and embolic events were numerically lower in the PPCA group, it was not statistically different. Considering the short follow-up duration (1 month), we could not draw a definitive conclusion. Thus, a large prospective study with a longer follow-up period is required to further explore the influence of PPCA.

Our results extend the application of PPAC to patients with anterior AMI and LV dysfunction after primary PCI. During the thrombolytic era, routine anticoagulation after fibrinolysis was suggested, ${ }^{20}$ but routine PPAC after primary PCI has been shown to have an unfavorable benefitrisk profile, ${ }^{21}$ and is not indicated in current STEMI guidelines. ${ }^{11}$ However, its use for specific indications, such as atrial fibrillation, LVT, mechanical heart valves, and deep venous thrombosis, is still indicated and has been examined by several previous studies. ${ }^{11,22,23}$ Our results suggested that PPAC after primary PCI in patients with anterior AMI and LV dysfunction may be necessary.

\section{Study Limitations}

Several should be emphasized. First, as a non-randomized retrospective observational analysis, this study cannot prove causality. Although multiple adjustments were performed to account for differences between groups, unmeasured confounders might be present. Second, the short-term follow-up limits the interpretation of the results. Third, the presence of LVT was detected by transthoracic echocardiography, which has limited sensitivity. Contrast-enhanced MRI is a better diagnostic modality with a higher sensitivity, but cost and availability limit its use in daily practice. ${ }^{24}$ 


\section{Conclusions}

Short-term PPAC using enoxaparin after primary PCI may be an effective and safe way to prevent LVT formation in patients with anterior AMI and LV dysfunction. Large prospective randomized trials are required to verify this finding.

\section{Disclosures}

The authors declare no conflict of interest.

\section{IRB Information}

The present study has been granted an exemption from requiring ethics approval. Name of the Ethics Committee: Department of Medical Administration Research Ethics Committee. Reference number: none.

\section{References}

1. McCarthy CP, Vaduganathan M, McCarthy KJ, Januzzi JL Jr, Bhatt DL, McEvoy JW. Left ventricular thrombus after acute myocardial infarction: Screening, prevention, and treatment. JAMA Cardiol 2018; 3: 642-649.

2. Robinson AA, Jain A, Gentry M, McNamara RL. Left ventricular thrombi after STEMI in the primary PCI era: A systematic review and meta-analysis. Int J Cardiol 2016; 221: 554-559.

3. O'Gara PT, Kushner FG, Ascheim DD, Casey DE, Chung MK, De Lemos JA, et al. 2013 ACCF/AHA guideline for the management of ST-elevation myocardial infarction: A report of the American College of Cardiology Foundation/American Heart Association Task Force on practice guidelines. $\mathrm{J} \mathrm{Am} \mathrm{Coll} \mathrm{Cardiol}$ 2013; 61: $78-140$.

4. Task Force on the Management of ST-segment Elevation Acute Myocardial Infarction of the European Society of Cardiology (ESC); Steg PG, James SK, Atar D, Badano LP, BlömstromLundqvist C, Borger MA, et al. ESC guidelines for the management of acute myocardial infarction in patients presenting with ST-segment elevation. Eur Heart J 2012; 33: 2569-2619.

5. Le May MR, Acharya S, Wells GA, Burwash I, Chong AY, So $\mathrm{DY}$, et al. Prophylactic warfarin therapy after primary percutaneous coronary intervention for anterior ST-segment elevation myocardial infarction. JACC Cardiovasc Interv 2015; 8: $155-162$.

6. Shavadia JS, Youngson E, Bainey KR, Bakal J, Welsh RC. Outcomes and prognostic impact of prophylactic oral anticoagulation in anterior ST-segment elevation myocardial infarction patients with left ventricular dysfunction. J Am Heart Assoc 2017; 6: e006054.

7. Moulson N, LaHaye SA, Bertrand OF, MacHaalany J. Prophylactic warfarin post anterior ST-elevation myocardial infarction: A systematic review and meta-analysis. Cardiovasc Revasc Med 2017; 18: 559-564

8. Kontny F, Dale J, Abildgaard U, Pedersen TR. Randomized trial of low molecular weight heparin (dalteparin) in prevention of left ventricular thrombus formation and arterial embolism after acute anterior myocardial infarction: The Fragmin in Acute Myocardial Infarction (FRAMI) Study. J Am Coll Cardiol 1997; 30: $962-969$.

9. The SCATI (Studio Sulla Calciparina Nell'Angina E Nella Trombosi Ventricolare Nell'Infarto) Group. Randomized controlled trial of subcutaneous calcium-heparin in acute myocardial infarction. Lancet 1989; 2: 182-186.

10. Turpie AG, Robinson JG, Doyle DJ, Mulji AS, Mishkel GJ, Sealey BJ, et al. Comparison of high-dose with low-dose subcutaneous heparin to prevent left ventricular mural thrombosis in patients with acute transmural anterior myocardial infarction. $N$ Engl J Med 1989; 320: 352-357.

11. Ibanez B, James S, Agewall S, Antunes MJ, Bucciarelli-Ducci C, Bueno $\mathrm{H}$, et al. 2017 ESC Guidelines for the management of acute myocardial infarction in patients presenting with ST-segment elevation: The Task Force for the Management of Acute Myocardial Infarction in Patients Presenting with ST-segment Elevation of the European Society of Cardiology (ESC). Eur Heart J 2018; 39: 119-177.

12. Chesebro JH, Knatterud G, Roberts R, Borer J, Cohen LS, Dalen J, et al. Thrombolysis in Myocardial Infarction (TIMI) Trial, Phase I: A comparison between intravenous tissue plasminogen activator and intravenous streptokinase. Clinical findings through hospital discharge. Circulation 1987; 76: 142-154.

13. Meurin P, Tabet JY, Renaud N, Weber H, Grosdemouge A, Bourmayan C, et al. Treatment of left ventricular thrombi with a low molecular weight heparin. Int J Cardiol 2005; 98: 319-323.

14. Shacham Y, Birati EY, Rogovski O, Cogan Y, Keren G, Roth A. Left ventricular thrombus formation and bleeding complications during continuous in-hospital anticoagulation for acute anterior myocardial infarction. Isr Med Assoc J 2012; 14: $742-746$.

15. White DC, Grines CL, Grines LL, Marcovitz P, Messenger J, Schreiber T. Comparison of the usefulness of enoxaparin versus warfarin for prevention of left ventricular mural thrombus after anterior wall acute myocardial infarction. Am J Cardiol 2015; 115: $1200-1203$.

16. Sørensen R, Hansen ML, Abildstrom SZ, Hvelplund A, Andersson $\mathrm{C}$, Jørgensen C, et al. Risk of bleeding in patients with acute myocardial infarction treated with different combinations of aspirin, clopidogrel, and vitamin $\mathrm{K}$ antagonists in Denmark: A retrospective analysis of nationwide registry data. Lancet 2009; 374: $1967-1974$.

17. Zhao HJ, Zheng ZT, Wang ZH, Li SH, Zhang Y, Zhong M, et al. Triple therapy rather than triple threat: A meta-analysis of the two antithrombotic regimens after stent implantation in patients receiving long-term oral anticoagulant treatment. Chest 2011; 139: $260-270$.

18. Porter A, Konstantino Y, Iakobishvili Z, Shachar L, Battler A, Hasdai D. Short-term triple therapy with aspirin, warfarin, and a thienopyridine among patients undergoing percutaneous coronary intervention. Catheter Cardiovasc Interv 2006; 68: 56-61.

19. Chen PF, Tang L, Yi JL, Pei JY, Hu XQ. The prognostic effect of left ventricular thrombus formation after acute myocardial infarction in the contemporary era of primary percutaneous coronary intervention: A meta-analysis. Eur J Intern Med 2020; 73: $43-50$

20. Antman EM, Morrow DA, McCabe CH, Murphy SA, Ruda M, Sadowski Z, et al. Enoxaparin versus unfractionated heparin with fibrinolysis for ST-elevation myocardial infarction. $N$ Engl J Med 2006; 354: 1477-1488.

21. Ducrocq G, Steg PG, Van't Hof A, Zeymer U, Mehran R, Hamm CW, et al. Utility of post-procedural anticoagulation after primary PCI for STEMI: Insights from a pooled analysis of the HORIZONS-AMI and EUROMAX trials. Eur Heart $J$ Acute Cardiovasc Care 2017; 6: 659-665.

22. Lip GY, Huber K, Andreotti F, Arnesen H, Airaksinen KJ, Cuisset T, et al. Management of antithrombotic therapy in atrial fibrillation patients presenting with acute coronary syndrome and/or undergoing percutaneous coronary intervention/stenting. Thromb Haemost 2010; 103: 13-28.

23. Gajanana D, Rogers T, Iantorno M, Buchanan KD, Ben-Dor I, Pichard AD, et al. Antiplatelet and anticoagulation regimen in patients with mechanical valve undergoing PCI: State-of-the-art review. Int J Cardiol 2018; 264: 39-44.

24. Weinsaft JW, Kim HW, Crowley AL, Klem I, Shenoy C, Van Assche L, et al. LV thrombus detection by routine echocardiography: Insights into performance characteristics using delayed enhancement CMR. JACC Cardiovasc Imaging 2011; 4: $702-712$. 